\title{
NGUYÊN NHÂN VÀ GIẢI PHÁP CHO VẤN ĐỀ Ô NHIỄM VÀ CẠN KIỆT NGUỔN NƯớC
}

\author{
Hoàng Phương \\ LinhNguyễn Khánh \\ LinhNguyễn Thùy \\ LinhPhùng Thị Nhật \\ LinhTrương Khánh Linh
}

\author{
Trần Thị Ngọc Mai \\ Nguyễn Đức Mạnh \\ Nguyễn Trọng Minh \\ Lê Hồng Thảo My \\ Đặng Vĩnh Nam
}

\section{(B) $\underline{\underline{V N} \bar{E}}$}

Đại học Quốc gia Hà Nội, Việt Nam

Hà Nội, ngày 08 tháng 1 năm 2021;

Preprint DOI: https://osf.io/ph2rs

Trong thế giới hiện đại, song song với sự phát triển vượt bậc của công nghệ và kinh tế là sự cạn kiệt dần đều của các nguồn tài nguyên thiên nhiên qua thời gian. Và nước ngọt chính là một trong những nguồn tài nguyên đóng vai trò quan trọng đối với cuộc sống con người nhưng lại chưa có được nhiều sự chú ý xứng đáng. Một số báo cáo chỉ ra rằng, hàng năm lượng nước bình quân đầu người tại Bắc Phi và Tây Á giảm trên $30 \%$ và rất hiếm khi đạt $1.000 \mathrm{~m} 3$ mặc dù đây là cột mốc thể hiện ngưỡng khan hiếm nước nghiêm trọng (Sơn, 2020) "Tại Mỹ khoảng 40\% các sông tại thành phố Hoa Kỳ đang gặp tình trạng ô nhiếm nguồn nước. Bangladesh đang đối mặt với nguy co 1,2 triệu dân nước này phải sủ dụng nguồn nước ô nhiê̂m. Tại đây có đến $85 \%$ nguồn nước đã bi ô nhiễm "'(Thoan, 2021) Tại Việt Nam, mỗi năm số người tử vong vì thiếu nước sạch lên đến hơn 9.000 người, 200.000 là số người mắc ung thư do sử dụng nước bị ô nhiễm.(Eco248, 2021)

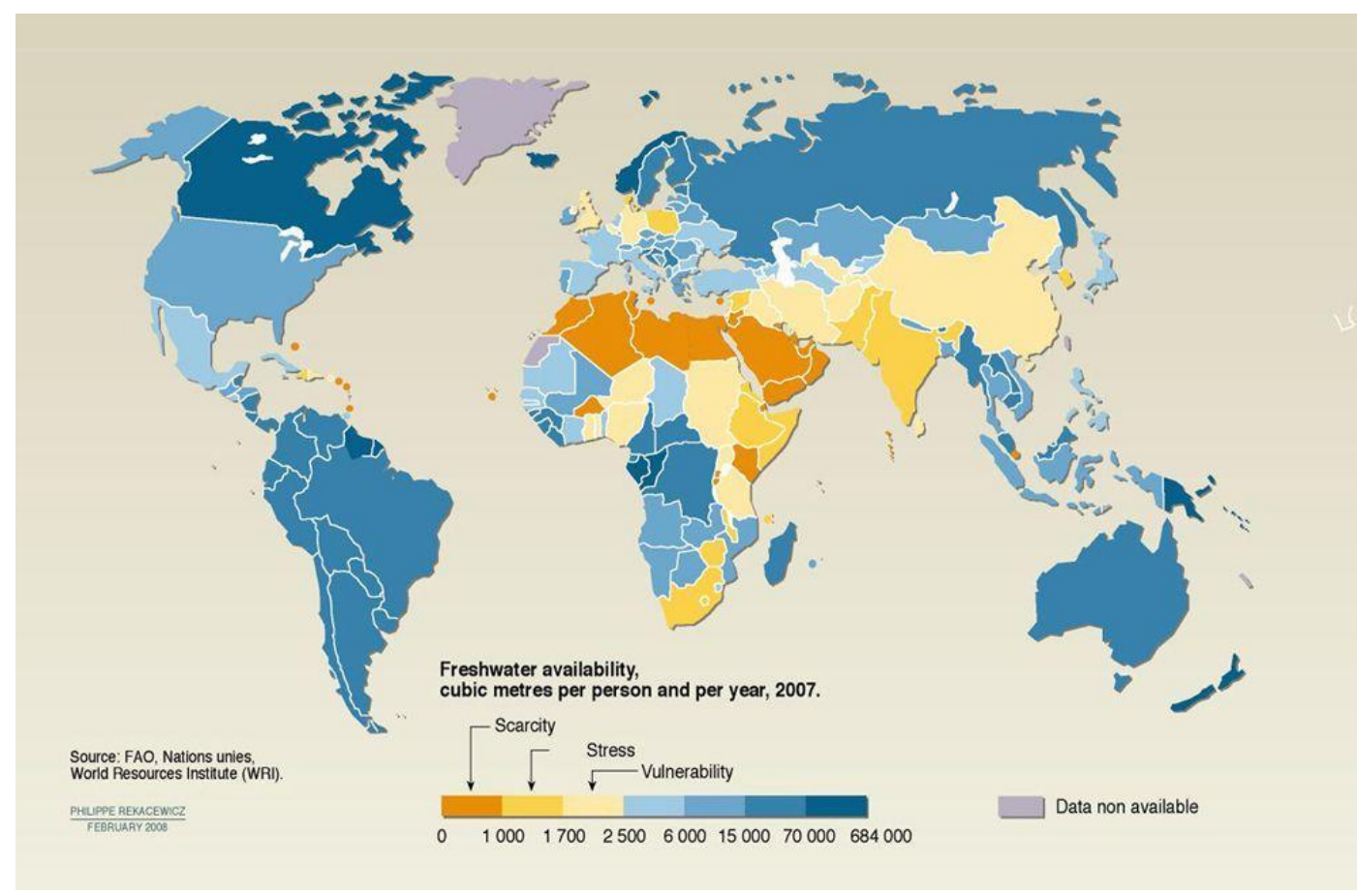


Hình 1. Bản đồ về mức độ đáp ứng đủ lượng nước sạch cần thiết cho mỗi người tại các quốc gia trên thế giới vào năm 2007.(Rekacewicz, 2008)

Nguyên nhân gây ra sự cạn kiệt về nước ngọt trên toàn cầu thì có rất nhiều. Nguyên nhân đầu tiên phải kể đến là do quá trình tăng dân số. Khi mức tiêu thụ tài nguyên tăng lên nhanh chóng thì thiên nhiên sẽ không thể kịp thời phục hồi lại nguồn tài nguyên. Cùng với đó, các chất độc hại từ lượng lớn rác thải sinh hoạt sẽ làm ô nhiễm nguồn nước ngọt. Liên Hợp Quốc cho biết, dân số thế giới năm 2050 tăng lên khoảng 22,2\% so với 2021, nghĩa là đạt khoảng 9 tỷ người trong năm đó và càng về sau thì dân số sẽ tăng ít đi. Do đó mà hiện nay dù đang được sinh sống tại các nước đang phát triển nhưng lại có hẳn 220 triệu người phải sống trong tình trạng thiếu nước sạch và gấp 5 lần số đó đang phải sống trong bầu không khí ô nhiễm đầy ngột ngạt (Nước, 2021).

Nguyên nhân thứ hai, mặc dù trình độ công nghệ xử lý rác thải đang ngày càng được mở rộng, nâng cao nhưng so với số lượng rác mà con người đang thải ra môi trường thì vẫn còn sự chênh lệch quá lớn. Không phải bất cứ quốc gia nào cũng đủ điều kiện để duy trì tốt quy trình xử lý rác thải đạt chuẩn cần có. Ngoài ra, văn hóa môi trường (Q. H. Vuong, 2021; Q. H. et al. Vuong, 2018) hạn chế là nguyên nhân quan trọng. Cụ thể đó là ý thức giữ gìn vệ sinh môi trường còn kém của người dân cũng sẽ dẫn đến sự cạn kiệt của tài nguyên nước ngọt nói riêng và tài nguyên thiên nhiên nói chung. Ví dụ như ngay tại Việt Nam hiện nay, công nghệ xử lý rác đang được áp dụng chủ yếu còn khá sơ đẳng. Lượng rác thải phần lớn được xử lý bằng cách đốt hoặc chôn lấp và những công nghệ này đạt hiệu quả chưa cao, thậm chí còn làm phát sinh thêm ô nhiễm. Xử lý rác thải là vấn đề nóng không chỉ ở Việt Nam mà còn trên toàn cầu.(Chi, 2021).

Nguyên nhân thứ ba là do sự phát triển nông nghiệp, công nghiệp và y tế. Rất nhiều các quốc gia sử dụng những loại phân bón, thuốc trừ sâu có nhiều hóa chất độc hại để chăm bón cây mà không để ý rằng những chất độc hại ấy sẽ ngấm vào đất và làm ô nhiễm nguồn nước ngầm. Về công nghiệp hóa, mặc dù sự phát triển của công nghiệp là để đáp ứng nhu cầu của con người nhưng lại làm tăng số lượng nước thải, dung dịch hóa chất dẫn đến nhiều nơi không được xử lý đúng cách và xả trực tiếp ra nguồn nước của chúng ta. Nước thải y tế từ các bệnh viện, phòng thí nghiệm luôn mang theo những mầm bệnh, virus hay là chất hóa học độc hại. Tất cả những nguồn thải ra đó nếu không được xử lý và kiểm tra một cách cẩn thận thì chắc chắn sẽ gây nên hậu quả ngôn lường cho không chỉ môi trường tài nguyên thiên nhiên mà còn là sức khỏe cộng động chung trên toàn cầu. Hàng năm lượng chất thải và nước thải công nghiệp thải ra ở các thành phố và thị trấn tại Trung Quốc - đất nước tỷ dân, được ước tính là tăng khoảng từ 23,9 tỷ m3 trong năm 1980 đến tận 73,1 tỷ m3 trong năm 2006 (Phụng, 2021). Ở Việt Nam, ô nhiễm rác thải từ các làng nghề, rác thải sinh hoạt nông thôn cũng là nguyên nhân quan trọng gây ra ô nhiễm nguồn nước. 


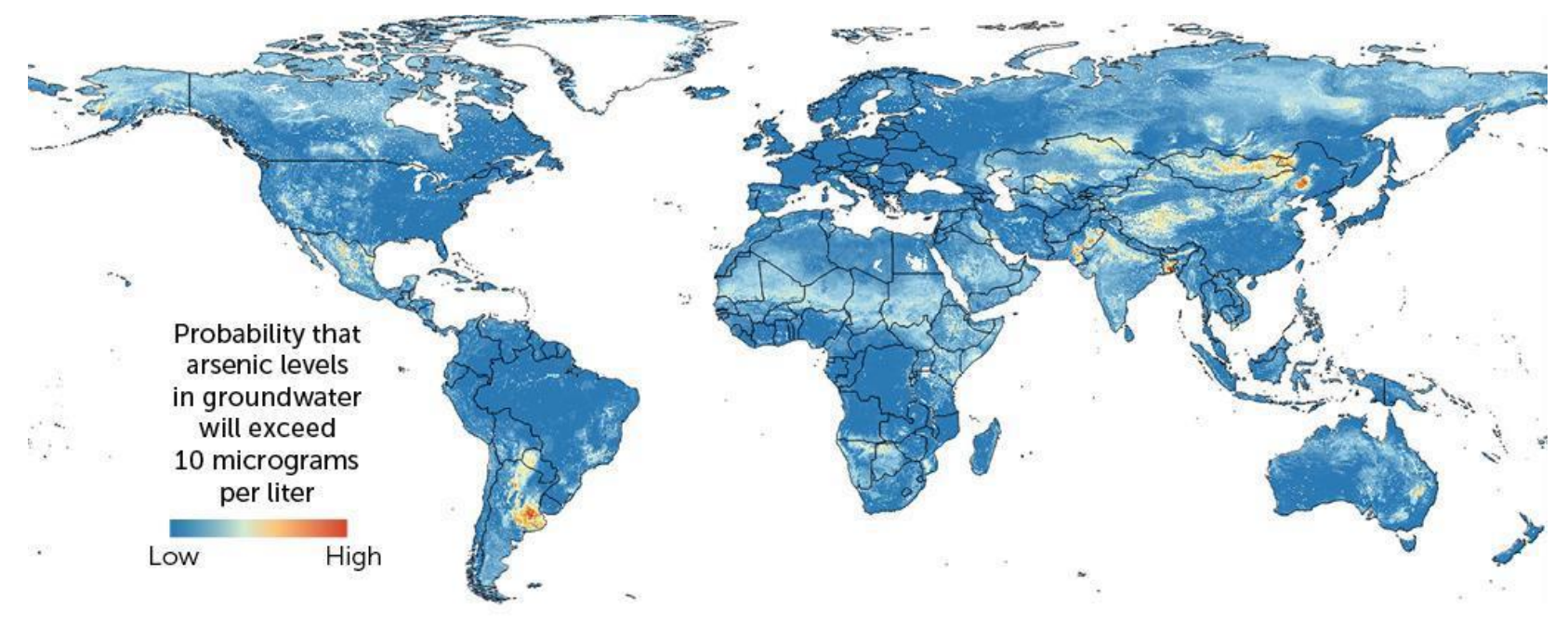

Hình 2. Bản đồ về những nơi có nguy cơ bị nhiễm thạch tín trong nước ngầm trên thế giới năm 2020.(Joel Podgorski, 2020)

Tại hội nghị thượng đỉnh về mục tiêu thiên niên kỷ (MDGs) diễn ra tại New York từ 2022/09/2010, nước không được dành vị trí xứng đáng trong các tài liệu hay kế hoạch hành động được công bố (Thiennhien.net, 2021) Theo Quỹ bảo vệ Môi trường EPF, chính sách phát triển đô thị và công nghiệp hóa của Trung Quốc làm cho hơn $1 \frac{1}{4}$ các nguồn nước tại đây bị ô nhiễm tới mức báo động và không thể dùng cho các sinh hoạt hàng ngày; $35 \%$ nước uống không bảo đảm là nước sạch.(Nhóm thực hiện Trường Đại học Nông Lâm Thành phố Hồ Chí Minh, 2013). Mâu thuẫn giữa các chính sách môi trường thể hiện ở thái độ tiêu dùng nguồn tài nguyên của con người. Nguồn nước sạch cạn kiệt bắt nguồn từ sự tiêu dùng bừa bãi, sự thiếu tự giác của con người trong trách nhiệm bảo vệ môi trường. Từ đó có thể kéo theo nhiều mâu thuẫn về quyền con người qua việc ảnh hưởng trầm trọng tới sức khỏe, chất lượng cuộc sống, an sinh xã hội của con người,... Một vài hậu quả có thể kể đến như những thiệt hại lớn về kinh tế, đói nghèo và di cư. Những điều này có thể làm gia tăng tranh chấp giữa các nhóm sắc tộc đối địch và ủy quyền cho chính quyền địa phương hoặc quốc gia, dẫn đến nguy cơ liên quan đến sự thất bại của nhà nước. Từ đó tạo điều kiện cho các nhóm bạo lực nổi lên để biện minh cho các hành động khủng bố hoặc làm cho tình hình quan giữa các quốc gia trở nên căng thẳng.(Middle East Monitor, 2019).

Hiện nay, vấn đề nguồn nước không đồng đều ở nhiều quốc gia đã gây ra một "cuộc chiến không có khói lửa" để tranh giành nguồn nước . Vì vậy, để duy trì sự phát triển bền vững của các quốc gia thì vấn đề chia sẻ nguồn nước là vô cùng cần thiết. Để đảm bảo vấn đề quản trị và chia sẻ hệ thống nguồn nước xuyên quốc gia hợp lý và hiệu quả, thì các quốc gia trên thế giới đã cùng nhau ban hành và ký kết nhiều văn bản quốc tế ràng buộc việc chia sẻ nguồn nước dựa trên mặt pháp lý như: Công ước New York 1997, Hiệp định sông Mê Công 1995, Công ước Helsinki 1992,...(Vụ Luật pháp và Điều ước quốc tế - Bộ Ngoại giao, 2015) Năm 1995, Hiệp định "Hợp tác phát triển bền vững lưu vực sông Mê Kông” giữa Campuchia, Lào, Việt Nam và Thái Lan được ký kết và được xem như là một hiệp định hợp tác lưu vực sông tiến bộ trên thế giới. Hiệp định đề ra các điều khoản cụ thể trong việc khai thác và sử dụng tài nguyên nước, trách nhiệm và quyền lợi của các bên đều phục vụ mục tiêu phát triển bền vững lưu vực, nhưng phải đi cùng với yêu cầu bảo vệ môi trường. "Công ước về Luật sư dụng các nguồn nước liên quốc gia cho các muc đỉch phi giao thông thủy năm 1997 là công ước toàn cầu đầu tiên điều chỉnh quan hệ giữa các quốc gia trong việc sử dụng nguồn nước liên quốc gia một cách công bằng, hợp lý giữa thượng lưu và hạ lưu, cùng với đó là thực hiện các nghĩa vu dựa trên nguyên tắc quốc tế."(Nguyễn Chiến Thắng, 2021) Năm 2012, Nhà nước ban hành Luật Tài nguyên nước với điểm mới về chính sách bảo vệ tài nguyên nước 
là công cụ kinh tế đã được áp dụng vào thực tế nhằm nâng cao hiệu quả quản lý và bảo vệ nguồn nước. Nguyên tắc "người dùng nước phải trả tiền" đã được đưa vào quy định của Luật năm 2012 theo quy định về "Tiền cấp quyền khai thác". Nước đã được xem như là sản phẩm hàng hóa với các chính sách giữ gìn và phát triển nguồn tài nguyên này được thực hiện theo hướng xã hội hóa; có chính sách khuyến khích các tổ chức, cá nhân tham gia phát triển các dịch vụ về nước và sử dụng nước tiết kiệm, hiệu quả.(Cục Quản lí tài nguyên nước - Bộ Tài nguyên và Môi trường, 2014).

Nhận thức được tầm quan trọng cũng như sự giới hạn của tài nguyên nước ngọt, nhiều quốc gia trên thế giới đã chung tay xây dựng nên các chính sách, hợp tác cùng nghiên cứu để tìm ra các giải pháp nhằm duy trì và bảo vệ nguồn tài nguyên quý giá này. Ví dụ như áp dụng công nghệ tối tân vào việc tái tạo nguồn nước cũng như sử dụng tiết kiệm nước nổi bật là: Israel đã thoát khỏi tình trạng thiếu nước nhờ sử dụng công nghệ tưới nhỏ giọt để tiết kiệm nước và tạo ra nước thông qua việc khử mặn nước biển, Singapore đã thành công xử lý nước thải thành nước tinh khiết có thể uống được,... Việt Nam là một trong những quốc gia tham gia tích cực nhất trong "cuộc chiến" bảo vệ nguồn nước bằng các biện pháp vô cùng hữu hiệu như: tăng cường các chế tài xử lý hành vi vi phạm về luật bảo vệ tài nguyên nước, giáo dục ý thức bảo vệ và tiết kiệm nước của người dân, kêu gọi các đoàn thể cùng chung tay góp sức bảo vệ nguồn nước...(Healthy Water, 2020)

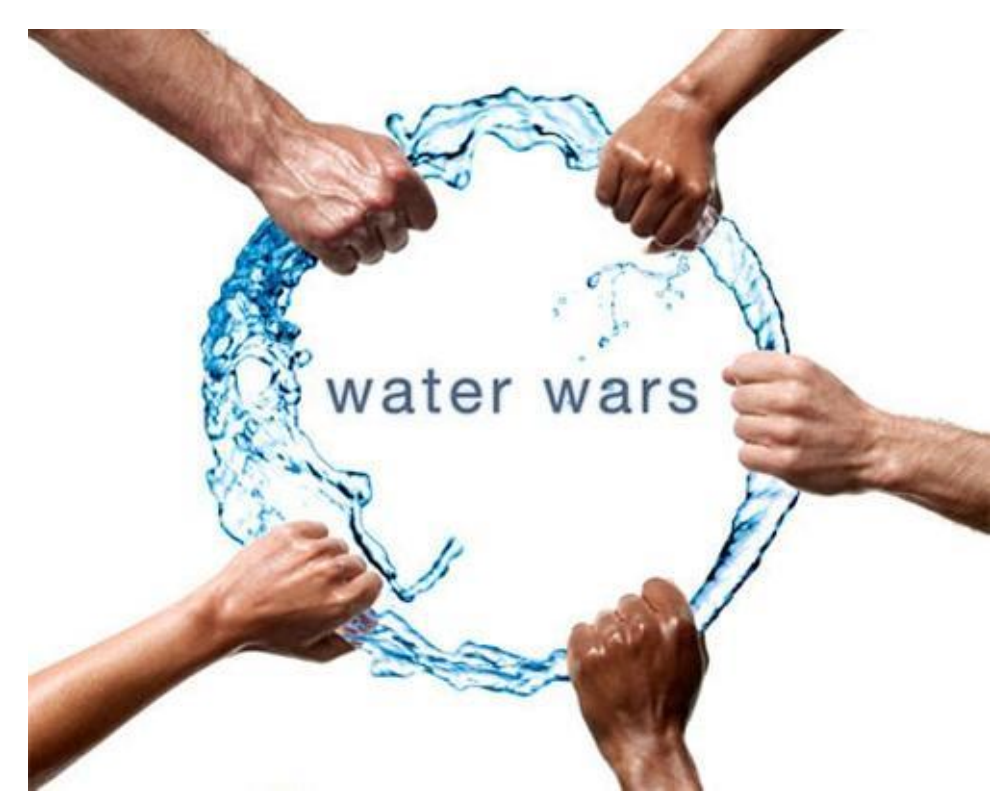

Hình 3. Bảo vệ nguồn nước là cách bảo vệ cuộc sống của chính chúng ta. (Nguồn: ctnkh.com.vn)

Theo Điều 26 trong Bộ Luật Tài nguyên nước Việt Nam 2012 về phòng, chống ô nhiễm, cạn kiệt nguồn nước: "Hoạt động khai thác, sủ dụng tài nguyên nước phải tuân thủ quy hoạch tài nguyên nước đã được cấp có thẩm quyền phê duyệt; nếu làm suy giảm chức năng của nguồn nuớc phải có trách nhiệm khắc phục hậu quả, nếu gây thiệt hại thì phải bồi thuờng theo quy định của pháp luật. "(Theo Bộ Luật Tài Nguyên Nước Quốc Hội Ban Hành Năm 2012, Căn Cứ Hiến Pháp Nước Cộng Hoà Xã Hội Chủ Nghĩa Việt Nam Năm 1992 Đã Được Sửa Đổi, Bổ Sung Một Số Điều Theo Nghị Quyết Số 51/2001/QH10, 2012). Bên cạnh việc thiết lập và hoàn thiện các chế tài xử lý hành 
vi nguy hại đến môi trường nước, nhà nước Việt Nam cũng có một số kế hoạch cải thiện hệ thống xử lý nước sạch. Cụ thể hơn là để giải quyết vấn đề cạn kiệt nguồn nước tại các lưu vực sông thuộc địa, nhà nước ta đã đưa ra một số biện pháp quy hoạch và hoàn thiện các công trình thủy điện, thủy lợi, hệ thống hồ chứa,... đồng thời kết hợp với việc xây dựng và thực hiện các chính sách đầu tư phù hợp để chung tay bảo vệ nguồn nước sạch, sử dụng tài nguyên hiệu quả, tiết kiệm hơn.

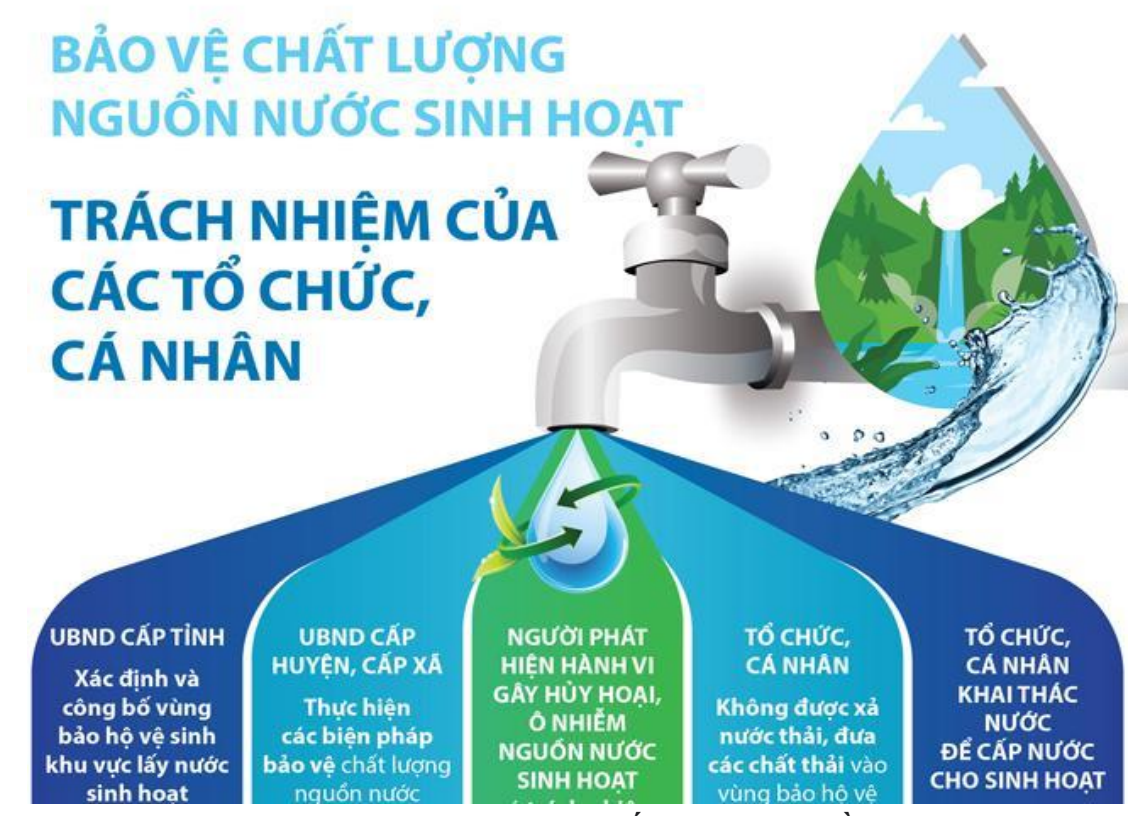

Hình 4. Ai sẽ có trách nhiệm bảo vệ chất lượng nguồn nước sinh hoạt? (Nguồn:

baotintuc.vn)

Bảo vệ nguồn nước sạch không phải việc riêng của một cá nhân, tổ chức hay đoàn thể nào mà là của chung xã hội, của cả cộng đồng. Vì vậy, để giải quyết các vấn đề môi trường trên một số gợi ý chính sách chung cần thực hiện như sau. Thứ nhất cần có kế hoạch quy hoạch sử dụng tài nguyên nước một cách hợp lý. Muốn vậy, cần có các điều tra, nghiên cứu công phu về nhận thức, nhu cầu và sự tự nguyện của người dân trong việc tham gia cải thiện nguồn nước (Khuc, 2013). Thứ hai, cần ứng dụng hệ xử lý thông tin $3 \mathrm{D}(\mathrm{Q}$. H. Vuong \& Napier, 2014) và nguyên lý bán dẫn giá trị (Khuc, 2022; Q. H. Vuong, 2021) để tìm kiếm các giải pháp sáng tạo cho cải thiện nguồn nước ngọt bị ô nhiễm. Thứ ba, đầu tư mạnh mẽ vào nghiên cứu, khoa học và giáo dục $(\mathrm{Q}$. $\mathrm{H}$. Vuong, 2018) để không chỉ gia tăng chất lượng thông tin, cải thiện chất lượng nguồn nhân lực mà còn xây dựng (chuyển đổi) văn hóa môi trường cho thế hệ trẻ (Q. Vuong, 2020). Cuối cùng, (các) chính phủ cần đưa ra kịp thời những chính sách ưu đãi, khuyến khích cộng đồng sử dụng nước tiết kiệm để giảm thiểu tối đa sự tác động tiêu cực đến nguồn nước sạch tự nhiên.

\section{TÀI LIỆU THAM KHẢO}

Chi, L. (2021, January 8). Giải pháp nào cho xủ lí rác thải tại Việt Nam. Báo Lao Động. https://laodong.vn/moi-truong/giai-phap-nao-cho-xu-ly-rac-thai-tai-viet-nam-977017.ldo

Cục Quản lí tài nguyên nước - Bộ Tài nguyên và Môi trường. (2014, January 7). Quản lí tổng hợp tài nguyên nuoóc và chính sách bảo vệ nguồn nước quốc gia. Hội Thảo "Quốc Hội Với Việc Đị̣nh Hình Cơ Chế Mới về Quản Trị Nước."

http://www.dwrm.gov.vn/uploads/download/files/11-quan-ly-tong-hop-tai-nguyen-nuoc-vachinh-sach-bao-ve-nguon-nuoc-quoc-gia_chau-tran-vinh_vn.doc

Eco248. (2021, January 8). Thự trang ô nhiê̂m môi trương nước ở Việt Nam hiện nay. Eco248. https://eco248.com/thuc-trang-o-nhiem-moi-truong-nuoc-o-viet-nam-hien-nay

Healthy Water. (2020, January 8). Các giải pháp bảo vệ môi trương nước tại Việt Nam. Healthy 
Water.

Joel Podgorski, M. B. (2020). Global threat of arsenic in groundwater. Science, 368, 845. https://www.science.org/doi/full/10.1126/science.aba1510

Khuc, Q. Van. (2013). Household's willingness-to-pay estimation for safe drinking water: A case study in Vietnam [Colorado State University, Fort Collins]. In ProQuest. http://search.proquest.com/docview/1413324084?accountid=48290 LA - English

Khuc, Q. Van. (2022). Về khả năng ứng dụng của hệ xử lý thông tin 3D và nguyên lý bán dẫn giá trị trong tìm kiếm giải pháp cho vấn đề ô nhiễm môi trường và biến đổi khí hậu ở Việt Nam. Tạp Chí Kinh Tế và Dự Báo, 1-5. https://kinhtevadubao.vn/ve-kha-nang-ung-dungcua-he-xu-ly-thong-tin-3d-va-nguyen-ly-ban-dan-gia-tri-trong-tim-kiem-giai-phap-cho-vande-o-nhiem-moi-truong-va-bien-doi-khi-hau-o-viet-nam-20840.html

Middle East Monitor. (2019, January 7). Water scarity and conflict: Not such a straightforward link. ECDPM. https://www2.hcmuaf.edu.vn/data/quoctuan/Tai nguyen nuoc va hien trang su dung nuoc.pdf

Nguyễn Chiến Thắng, H. G. M. (2021, January 8). Bài 3: Bảo vệ nguồn nước là bảo vệ sự sống. Báo Quân Đội Nhân Dân. https://www.qdnd.vn/xa-hoi/cac-van-de/bai-3-bao-ve-nguonnuoc-la-bao-ve-su-song-654725

Nhóm thực hiện Trường Đại học Nông Lâm Thành phố Hồ Chí Minh. (2013, January 8). Tài nguyên nước và hiện trạng sủ dụng nước. https://www2.hcmuaf.edu.vn/data/quoctuan/Tai nguyen nuoc va hien trang su dung nuoc.pdf

Nước, C. quản lí tài nguyên. (2021, January 8). Nước ngọt - nguồn tài nguyên đang cạn kiệt. Cục Quản Lí Tài Nguyên Nước. http://dwrm.gov.vn/index.php/vi/news/Tai-nguyen-nuoc/Nuocngot-nguon-tai-nguyen-dang-can-kiet-189/

Phụng, T. H. K. (2021, January 8). Thục trạng ô nhiếm môi truờng nước vè trách nhiệm bảo vệ nguồn nước sạch. Cổng Thông Tin Điện Tử Quận Tân Bình. https://tanbinh.hochiminhcity.gov.vn/web/neoportal/danh-muc-tin-tuc-su-kien//asset_publisher/VN5j2Vj9DHkT/content/thuc-trang-o-nhiem-moi-truong-nuoc-va-trachnhiem-bao-ve-nguon-nuoc-sach?inheritRedirect=false

Theo Bộ Luật Tài nguyên nước Quốc Hội ban hành năm 2012, căn cứ Hiến pháp nước Cộng hoà xã hội chủ nghĩa Việt Nam năm 1992 đã được sửa đổi, bổ sung một số điều theo Nghị quyết số 51/2001/QH10, (2012).

Rekacewicz, P. (2008, January 8). Freshwater Availability. National Geographic Social. https://www.nationalgeographic.org/photo/waterstress-2008-unep/

Sơn, N. (2020, January 8). FAO kêu gọi nhanh chóng giải quyết tình trạng thiếu nước trên toàn cầu. Kiếm Toán Nhà Nước. http://baokiemtoannhanuoc.vn/quoc-te/fao-keu-goi-nhanhchong-giai-quyet-tinh-trang-thieu-nuoc-tren-toan-cau-146147

Thiennhien.net. (2021, January 8). Khan hiếm nước - thách thức toàn cầu. Trang Tin Điện Tử Của Ủy Ban Dân Tộc.

http://web.cema.gov.vn/modules.php?name=News\&op=Print\&mid=3710\&fbclid=IwAR3F OtujXLPNgXFkBmymJ3Qy_Uc6TVQOc3cj3cga8BhHrIOrnPiBs6xrfCo

Thoan, V. (2021, January 8). Thực trạng ô nhiếm môi trường nước hiện nay. Môi Trường CCEP. https://ccep.com.vn/thuc-trang-o-nhiem-moi-truong-nuoc/

Vụ Luật pháp và Điều ước quốc tế - Bộ Ngoại giao. (2015, January 8). Tổng quan hệ thống điều ước quốc tế liên quan đến quản trị nguồn nước và nhũng vấn đề đặt ra trong quá trình hội nhập quốc tế.

http://www.vncold.vn/Modules/CMS/Upload/10/TuLieu/150803/ThamLuanBoNgoaiGiao.p df

Vuong, Q. (2020). From children's literature to sustainability science, and young scientists for a more sustainable Earth From children's literature to sustainability science, and young scientists for a more sustainable Earth. Journal of Sustainability Education, 24(December), 2019-2021.

Vuong, Q. H. (2018). The (ir)rational consideration of the cost of science in transition economies. Nature Human Behaviour, 2(1), 5. https://doi.org/10.1038/s41562-017-0281-4

Vuong, Q. H. (2021). The semiconducting principle of monetary and environmental values 
exchange. Economics and Business Letters, 10(3), 284-290.

https://doi.org/10.17811/ebl.10.3.2021.284-290

Vuong, Q. H. et al. (2018). Cultural additivity: behavioural insights from the interaction of Confucianism, Buddhism and Taoism in folktales. Palgrave Communications, 4(143). https://doi.org/10.1057/s41599-018-0189-2

Vuong, Q. H., \& Napier, N. K. (2014). Making creativity: the value of multiple filters in the innovation process. International Journal of Transitions and Innovation Systems, 3(4), 294327. https://doi.org/10.1504/ijtis.2014.068306 